\title{
Las dos Emmas: vida, trabajo y ficción
}

\section{- Fermín A. Rodríguez \\ Conicet/UBA}

Fecha de recepción: 25 de octubre de 2017. Fecha de aceptación: 20 de agosto de 2018.

\begin{abstract}
Resumen
La revelación por parte de "la obrera Zunz", el personaje del cuento de Borges, de un poder de invención y de una iniciativa para actuar inédita para alguien de su clase y de su género, y su promoción de obrera textil a creadora y protagonista de una minuciosa urdimbre ficcional introducen una operación de desidentificación que la saca de la baja visibilidad en la que viven los sujetos anónimos de la literatura social. Esta duplicidad de Emma reaparece en la duplicidad de un relato lleno de dobleces, porque al desacuerdo entre la Emma que políticamente cuenta y la Emma que no cuenta para nada, le corresponde un desacuerdo literario entre dos tipos de relato: las tramas sin hilos sueltos de la literatura autónoma, diseñadas en torno a un principio de verosimilitud fuerte, y el texto impersonal de una ficción que se pierde en el tejido laxo de afectos y sensaciones de la vida moderna.
\end{abstract}

Palabras clave:

Emma Zunz, Jorge Luis Borges, trabajo y género, procesos de desidentificación, formas de disenso.

\begin{abstract}
The "worker Zunz", the main character in Borges'story "Emma Zunz", is promoted from textile worker to creator and protagonist of a meticulous fictional fabric. Emma is endowed with an unprecedented power of invention for someone of her class and gender, by which Emma is desidentified and removed from the low visibility in which anonymous subjects of social literature use to live. This duplicity of Emma reappears in the duplicity of a story full of folds, because the disagreement between the Emma that politically counts and the Emma that does not count at all, corresponds to a literary disagreement between two types of story: the tightened plots typical of autonomous literatures, woven around a strong principle of verisimilitude, and the loose text of modern fictions, frayed at its edges because literature becomes life.
\end{abstract}




\section{Un cuento sobre nada}

Del lado de las peripecias, de la riqueza de la aventura, de los cambios de fortuna inesperados, del suspenso y del ocio improductivo, la ficción novelesca se opuso al orden rutinario del trabajo. El tiempo de la ficción comienza después del trabajo y del descanso reparador de las fuerzas, cuando termina la jornada laboral y se abre para los trabajadores la posibilidad de una vida no administrada, separada parcialmente de los imperativos disciplinarios de la producción. Porque en el mundo prosaico de la fábrica o de la oficina o, después del trabajo, en el mundo repetitivo y trivial de los hábitos y los acontecimientos materiales, nunca pasa nada lo suficientemente novelesco como para cruzar el umbral de visibilidad que inaugura una ficción.

Campo de indagaciones de las ciencias sociales y sus relatos, el mundo gris de la actividad productiva donde reside, desde Marx, el principio de racionalidad que gobierna la sociedad, resulta invisible para el régimen de identificación de sujetos, objetos y acciones que constituyen los mundos autónomos de las ficciones literarias. "No hay historia posible en el mundo del trabajo", señala Piglia en esta lógica, a propósito de Arlt y su economía literaria (1993: 124). El trabajo capitalista solo produce miseria, y esa verdad última de la sociedad pesa sobre las literaturas sociales que, al borde de su anulación como ficciones, recogen entre sus páginas los acontecimientos de la existencia cotidiana que en su insignificancia y su carácter imperceptible están excluidos del régimen de sentido de la novela. El dinero es el mejor novelista del mundo a condición de no ser el fruto de un salario; y los hombre que viven de su sueldo - remataba Piglia en "La ficción del dinero"-son personajes insignificantes que "no tienen nada que contar" (ibídem: 125) porque no cuentan para nada.

Pero una contemporánea de las aventuras de Silvio Astier, "la obrera Zunz", cuenta otra historia de una manera diferente. Emma Zunz, la joven virgen justiciera del cuento de Borges que en la lógica del crimen perfecto mata a su patrón para vengar la muerte de su padre, es uno de esos seres insignificantes "sin historia" que viven de su salario y que en su anonimato de trabajadora textil no tiene en principio nada que contar, ni siquiera bajo la forma de la aventura amorosa: a punto de cumplir 19 años, Emma tiene un "temor casi patológico" (ibídem: 70) a los hombres. ${ }^{1}$ La vida de Emma, que hacia 1922 va a cumplir 19 años, se reparte según una serie de repeticiones monótonas que se suceden a un ritmo prefijado por la alternancia entre el trabajo en la fábrica y el descanso.

En el tiempo en el que habita Emma, toda potencia de invención y variación se encuentra en principio neutralizada y codificada. Lo que pasa frente a los telares mecánicos y las máquinas de coser de la fábrica de tejidos Tarbuch y Loewenthal; los viajes en tranvía de ida y de vuelta al trabajo; las horas de sueño y de descanso que su cuerpo necesita para reponer energías; las salidas al cine con sus amigas los domingos, no deberían tomar la forma del acontecimiento en tanto pertenecen a esa vaga constelación de tiempos y espacios organizados alrededor de las repeticiones del hábito y del ocio administrada por la cultura de masas. Son esos tiempos muertos, momentos cualesquiera que para el Borges de "El arte narrativo y la magia" o del "Prólogo" de la novela de Adolfo Bioy Casares La invención de Morel vuelven inaceptable como invención cualquier acumulación textual de detalles triviales a los que el lector de novelas realistas se resigna "como a lo insípido y ocioso de cada día" (Borges, 2006: 8).

1 En la lengua inglesa, "soltera” y "trabajadora textil” se anudan en un mismo término, a saber, spinster. Proviene de spin ("hilar"), un trabajo tradicionalmente femenino realizado por mujeres solteras cuyo uso se extiende a cualquier mujer que no se ha casado. Soltera e hiladora, Emma también tejerá una ficción sin dejar hilos sueltos: textus en latín significa "tejido", "entramado". 
Sin embargo, la muerte de su padre por una sobredosis accidental de veronal, que Emma, sin más pruebas que unas pocas líneas en una carta con un remitente impreciso, no vacila en tomar por un suicidio, la arroja al campo del acontecimiento, donde la muerte de Emmanuel Zunz, ex cajero de la fábrica y falso culpable de una estafa cometida tiempo atrás por el actual patrón de Emma, "era lo único que había sucedido en el mundo, y seguiría sucediendo sin fin" (Borges, 2001a: 69). Emma tendría a partir de entonces algo para contar, una historia donde las cosas sucederían de acuerdo con una lógica orgánica de las acciones que no es la de la simple sucesión empírica de los hechos. En apenas una noche, robándole horas de descanso al sueño, en el tiempo que una trabajadora no tiene - "No durmió aquella noche, y cuando la primera luz definió el rectángulo de la ventana, ya estaba perfecto su plan" (2001a: 70)-, Emma trama, dueña de sí y en pleno control de herramientas textuales que no se supone que debería tener, uno de esos rigurosos objetos artificiales sin partes injustificadas que separan la obra de arte autónoma del modernismo de lo que Borges identifica con el pleno desorden de la literatura realista, "la morosa novela de caracteres" (1982: 88) o novela de "simulación psicológica", donde cualquier vida y cualquier detalle por más insignificante que fuese puede ser la materia de una escritura que "propende a ser informe" (2001a:8).

En este sentido, evoca a la distancia a otra Emma - la Emma Bovary de la novela de Flaubert-, la burguesa de provincia buscando vivir otra forma de vida que no se correspondía con su identidad. Ambas pertenecen a un mismo linaje de mujeres jóvenes y plebeyas que, en medio de las luchas feministas y obreras por la igualdad, reconstruyen sus experiencias cotidianas con la multitud de pasiones, valores, palabras, placeres y aspiraciones igualitarias que recorren la sociedad de masas.

Para ellas, la ficción es inseparable de un nuevo real, un modo de ver, de nombrar y de actuar sobre el tejido viviente de un mundo sensible modelado por una cultura de masas donde la cuestión de la mujer y del género se repite con insistencia. Después de todo, ¿las multitudes no son femeninas? En La Pychologie des foules (1895), el influyente estudio de fines del siglo XIX de Gustave Le Bon, el miedo burgués a las masas urbanas es indiscernible del temor del hombre a una mujer como la Emma hija de inmigrantes de los años veinte que, en su rol de soltera y trabajadora, no se ajusta al modelo de cuerpo dócil y sexualmente pasivo de la madre y la esposa ama de casa (Huyssen, 103).

Claro que Emma Zunz no es exactamente Emma Bovary: están separadas por dos concepciones de la literatura y de la ficción, que corresponden al cuento y la novela como géneros. La Emma de la novela de Flaubert exige que la vida se fusione con la literatura en una sola realidad donde los placeres estéticos dejen de ser un objeto ideal de contemplación para convertirse en algo material y concreto. Quiere vivir con la misma intensidad de lo que lee. No hay, para el personaje de Madame Bovary, confusión de ningún tipo entre literatura y realidad -el "mal francés" que, según la crítica que le hace Rancière (2007), el Borges formalista y francófobo encuentra en la literatura francesa, en desacuerdo con su propia concepción autónoma del cuento como artificio. Lo que sí hay, para la Emma de Rouen, es una puesta en cuestión del esquema que separa los seres activos capaces de grandes acciones y pasiones exquisitas, y los seres pasivos como ella a quienes las cosas simplemente les pasan, tan insignificantes como los detalles sin función que apuntalan el célebre "efecto de realidad" que Barthes se dedica a desmontar en su clásico análisis de los excesos descriptivos de la novela realista (Rancière, 2015).

Pero en esa realidad prosaica que invade el relato y lo sobrecarga de objetos y palabras superfluas, no hay que ver tanto el triunfo como la ruina de la poética de la representación. En efecto, en la democracia narrativa de Flaubert, dice Rancière en El hilo 
perdido, para escándalo de los detractores del detalle sin función, cualquiera "puede experimentar cualquier sentimiento, cualquier emoción o pasión" (2015: 25), porque en el medio igualitario de la prosa flaubertiana, la distinción entre cosas poéticas y prosaicas, entre experiencias ordinarias y extraordinarias, entre afectar y ser afectado, se encuentra suspendida. Ansiosa de "verificar en la vida algunas palabras robadas a los libros destinados a las almas de élite" (Rancière, 2015: 26), Emma Bovary se niega a separar de la vida las intrigas amorosas y los placeres sensibles que encuentra en el arte y la literatura. Su concepción de la ficción es impura, y bajo el presupuesto de la igualdad sensible (entre detalles, entre personajes), se rebela contra las jerarquías que ponen a la educación estético-sentimental de las grandes damas de la capital por encima de la capacidad de tener experiencias de una joven burguesa de provincia.

Emma Zunz, por su parte, es la hija de los inmigrantes socialistas y anarquistas de principios de siglo. Vive sola, trabaja en una fábrica textil, es socia de un club de mujeres y los fines de semana sale con sus amigas a ver las películas de Milton Sills, una estrella del cine mudo cuyo retrato atesora en el cajón de la cómoda. El cine, esa "infinita novela espectacular que compone Hollywood" y que, en la misma lógica que los relatos de breves páginas que Borges cultiva en su literatura, "las ciudades releen" (Borges, 1982: 88), es para Emma lo que los folletines del siglo XIX eran para su antecesora: un modelo de experiencia entretenido y racional a la vez; un guion para sus deseos y sus romances que viene de los géneros de la cultura de masas y que las Emmas del mundo aplican a la vida (Louis, 1997).

Pero lo importante para Emma es que la revelación - a medida que se despliega la trama de un poder de invención y de una iniciativa para actuar inédita para alguien de su clase y de su género-introduce una operación de desidentificación que la saca de la baja visibilidad en la que viven los sujetos anónimos de la literatura social más tradicional. Su promoción de obrera textil a diseñadora y protagonista de una minuciosa urdimbre ficcional la proyecta a otro espacio que corresponde a un cuerpo distinto al cuerpo de la trabajadora adaptada a su rol.

El plan de ajusticiar a Loewenthal, a quien Emma atribuye la responsabilidad moral del suicidio, consiste en ir a visitarlo a última hora del sábado cuando la fábrica está vacía y, aprovechando la ausencia de testigos, matarlo de un balazo en legítima defensa por un abuso sexual en el que todos terminarán creyendo porque la historia que fraguó con su cuerpo sería "sustancialmente cierta" (76). Unas horas antes, siguiendo la lógica de los "cuidadosos relatos" donde todo episodio debe ser "de proyección ulterior" (El arte narrativo, 90), Emma se había acostado a cambio de dinero con un desconocido, no sin antes haberse inscripto en un club de natación y dejado constancia de su virginidad en la revisación médica. Por eso no miente del todo cuando llama para hacer la denuncia por haber sido abusada: "Verdadero era el tono de Emma Zunz, verdadero el pudor, verdadero el odio. Verdadero también era el ultraje que había padecido" (Borges, 2001: 76). Lo falso es el encadenamiento artificial de las acciones dispuesto por Emma, la apretada trama por medio de la cual la realidad del cuerpo y sus afectos queda anudada a la rigurosa construcción de un verosímil narrativo.

\section{Contratiempos: la costurerita que dio el mal paso}

¿Quién puede ver en la obrera Emma Zunz algo más que una víctima pura e inocente, y sospechar que la violación de Loewenthal fue una mera puesta en escena? ¿Quién puede dudar de la verdad de un argumento que no rompe, a simple vista, con el sentir en común de una sociedad que, según un reparto de roles y jerarquías, no atribuye a una chica de barrio común y corriente el poder de ser algo más que una víctima de 
las circunstancias, forzada a defenderse y a matar en defensa propia? "Ha ocurrido una cosa que es increíble... El señor Loewenthal me hizo venir con el pretexto de la huelga... Abuso de mí, lo maté..." (Borges, 2001: 76) -confiesa Emma, repitiendo lo que los lectores del realismo social y de las crónicas policiales están dispuestos a creer. Después de todo, en 1922, el año en el que transcurre la historia, Emma no parece ser más que una de esas mujeres del pueblo mudas e insignificantes que solo tienen la vida, encerradas en la sucesión monótona del trabajo y de los días por la ficción social dominante. Sus amigas pueden dar fe de su pacatería, que la narración señala al pasar. ¿Cómo puede ser la asesina fría y calculadora, capaz de prostituirse para poder llevar a cabo su venganza? Lo verdadero es inverosímil, la verdad -la potencia de invención de alguien como Emma- es imposible de creer.

Pero entonces, ¿qué quiere decir Emma cuando anuncia que lo que le acaba de suceder - visitar la fábrica un sábado a la noche, ser abusada, matar a Loewenthal-es "increíble"? O mejor dicho, ¿qué está haciendo con esa figura retórica que los gramáticos llaman lítote, al negar lo contrario que quiere decir, a saber, que le crean, que no duden de la veracidad de sus palabras? ¿Suspender la incredulidad del auditorio, como cuando decimos "no lo vas a poder creer", para introducir el relato de un acontecimiento extraordinario? Lo que está haciendo es una ficción, mostrando que, para hacer un cuento, con el rigor causal no alcanza: es necesaria cierta inversión de lo que se espera que pase, y que lo falso parezca verdadero por medio de la construcción de un verosímil.

De todas maneras, en una sociedad dispuesta a creer en el cuento de la virgen ultrajada, no es tan increíble que alguien como Loewenthal abuse del candor de una obrera, explotada por un patrón avaro e inescrupuloso (y judío, subraya Ludmer). La verosimilitud realista de la denuncia está de su lado. Tampoco es increíble que una mujer mate en defensa propia, sin cometer asesinato. Lo increíble, para la división de lo sensible, sería que alguien como Emma fuera dueña de un poder de decisión y un talento narrativo inverosímil para una persona de su condición. Emma lo sabe y cuenta con eso, y si alguien sospechara de sus palabras, como debería ocurrir si "Emma Zunz" fuera un cuento policial, encontraría que Loewenthal es el "falso culpable" del género en el que se sabe bien que las cosas nunca suceden como parece que suceden, que el crimen no ocurrió como parece que ocurrió. Llegado el caso, describir la violación como "increíble" no es negar lo opuesto de lo que se quiere afirmar, sino mentir con la verdad y hacer ficción con la fuerza de vida de la ficción.

En este sentido, "Emma Zunz" es portador de un disenso. El cuento cuyas acciones transcurren en la década de 1920 fue escrito a fines de la década de 1940, en los años del peronismo, cuando se está reconfigurando el campo de lo perceptible y lo pensable alrededor del cuerpo de los trabajadores, en especial de las obreras, y se discuten los usos y sentidos de las representaciones sociales. Ludmer lo señala a propósito de la serie de mujeres que matan de El cuerpo del delito, cuando observa que Emma, como si viviera en el futuro, goza en la década de 1920 de una cultura que las obreras argentinas "no van a adquirir hasta el 40, con el peronismo, cuando se escribe el texto" (Ludmer, 1999: 478). La posición de las mujeres en las estructuras económicas y jurídico-políticas del país había cambiado. En un mundo donde las trabajadoras constituían un tercio de la fuerza de trabajo industrial, el mapa que distribuye capacidades e incapacidades se ha modificado (Munck et al., 1987, en Ludmer, 1999, 391-92). En la industria textil el porcentaje de trabajadoras ascendía a más de la mitad, y los hombres, temerosos de "la creciente libertad de las mujeres que eran económicamente independientes", se preocupaban porque "el trabajo más barato de la mujer les podía quitar empleos" (Guy, 1994: 132, en Ludmer, 1999).

La Ley de Trabajo a Domicilio, que regula hasta nuestros días la actividad de las trabajadoras textiles como Emma, fue sancionada en 1941, por iniciativa del senador 
socialista Alfredo Palacios (Gago, 2014: 187). La ley de Voto Femenino fue promulgada en 1947, la época por la que Cecilia Ingenieros debe haberle contado a Borges el "argumento espléndido" (Borges, 2001: 199) de lo que terminaría siendo "Emma Zunz", el cuento que Borges se encargó de ejecutar y publicar primero en 1948 en la revista Sur, y un año más tarde entre los textos de ElAleph. ${ }^{2}$

El reconocimiento por parte de la ley de la igualdad jurídica entre géneros (la igualdad abstracta ante la ley), va por detrás de las luchas por la igualdad política que, a contrapelo del consenso establecido, son luchas por la redefinición de los roles sociales en momentos de cuestionamiento de la división social de actividades (Scavino, 1999). En esta nueva topografía de lo posible, donde el sistema de evidencias sensibles en el que habita Emma se ha modificado, "la costurerita que dio aquel mal paso" del poema de Carriego, evocada por Emma en su performance de virgen ultrajada, está en desacuerdo con la obrera textil, determinada y resuelta, que mata al patrón durante una huelga. El acto frío y razonado que hace de su cuerpo una "herramienta" de justicia no coincide con el "contratiempo orgánico-sentimental" de las costureras desengañadas de la cultura popular (Borges, 1987: 67). ${ }^{3}$

La Emma que no cuenta para nada, modosita e ingenua, a la que las cosas simplemente le pasan, no es la Emma que comete una ficción, la vengadora que habita en otro tiempo - un contratiempo-y otra vida bajo el disfraz de la Emma de siempre, en desacuerdo, aunque en forma indecidible, con las identificaciones socioculturales tradicionales. "Ya era la que sería" (Borges, 2001: 69), anuncia el narrador apenas Emma recibe la noticia de la muerte de su padre, anticipando la serie de "teatralerías" (Borges, 2001: 75) que interpreta a lo largo del plan. El movimiento es paradójico, porque en el linaje de las simuladoras de la literatura científica del siglo XIX y de las "políticas de la pose" (Molloy, 1994), Emma finge seguir obedeciendo al rol pasivo de la víctima del cual acababa de des-sujetarse. Recubierta de los significados que se le quieren endosar y que hace suyos, Emma seguirá interpretando un personaje que se limita a repetir los signos mudos que la sociedad escribe sobre su cuerpo. Pero incluso sin saberlo, dejó de creer en la mujer que los dictados de la ficción social dominante le decían que era, para volverse lo que no estaba en los planes de nadie: un agente libre de una política democrática que, como quien dice, se tomó la libertad, que por cierto nadie le dio, para actuar de otra manera hasta el punto de hacerse prostituta. ${ }^{4}$ Libertad que, en la lógica de la emancipación, es para Emma un presupuesto de la acción antes que una conquista o un reconocimiento totalmente inconveniente para ella, que solo desea volver a ser tragada cuanto antes por las repeticiones del hábito.

Indagación sobre el poder de los semblantes, "Emma Zunz" nos instala en el recorrido interminable del intervalo que separa lo real de la actuación, lo activo de lo pasivo, la literatura de la vida. Y lo real, parece decir el texto, es, siguiendo a Badiou (2005: 79), esa distancia mínima que una ficción como la de Borges no deja de recorrer. No hay un real aislable sobre el que Emma monta su simulación, sino una distancia mínima que, una vez abierta, inaugura lo que Badiou llamaría un proceso de igualdad, que es básicamente el rechazo silencioso de Emma de ser recluida en una identidad predefinida. Por eso, señala Scavino a propósito de los movimientos feministas (contemporáneos, por cierto, de la historia de Emma), "mujer" se convirtió, más que en una forma de identidad, en el nombre de una resistencia a las identificaciones establecidas, "a tal punto que cuestionó también el ser hombre" (Scavino, 1999: 40).

2 Acerca de la mujer como modelo imaginario de "engendramiento" de la ficción en Borges, ver Panesi (1997).

3 Acerca de "Emma Zunz" y el "mito de la caída" en los imaginarios del trabajo femenino en la Argentina de primera mitad del siglo XX, ver Angilletta (2018).

4 “¿Hay alguna manera acaso de hacer de puta sin hacerse puta?”, pregunta Kohan a propósito de Emma, localizando en ese punto "en el que el simulacro y la realidad ya no pueden distinguirse" una capacidad de la ficción de tocar algo del orden de la verdad (2013: 89-90). 
La duplicidad de Emma reaparece en la duplicidad de un relato lleno de dobleces. En efecto, al desacuerdo a nivel de la subjetividad entre la Emma que políticamente cuenta y la Emma que no cuenta para nada, le corresponde un desacuerdo literario entre dos tipos de relatos que se entretejen en el texto. Porque la increíble historia montada por Emma de la obrera joven e incauta que un sábado a la noche se mete engañada en la boca del lobo donde el patrón cruel y avariento la espera para abusarse de ella, no deja de ser una historia prosaica. A la manera de una de esas morosas novelas de caracteres que Borges despreciaba, el plan de Emma se basa en el paso "laborioso y trivial" del tiempo, fingiendo una concatenación de motivos que, observa Borges, "se proponen no diferir de los del mundo real" (1982: 88). Se levantó a la misma hora para ir a trabajar, se declaró "como siempre" en contra de la huelga que se estaba gestando; en la revisación médica, cuando había que reírse se rió, y cuando todas esperaban que se callara, se calló. Nada memorable debía ocurrir ese día ni a la mañana siguiente, y nada ocurrió. Incluso en el puerto, expuesta a la mirada de los hombres, Emma se pasea "inadvertida" por las calles del Bajo, con la atención puesta en "la rutina o los manejos" de las prostitutas (Borges, 2001: 72).

Paradójicamente, el plan de procurar que el día de la víspera "fuera como los otros" (ibídem: 70) y que la vida y sus rutinas desaparezcan "transformándose en nada", como diría Shklovsky (2002: 60), está en tensión con el principio de acción al que Emma se consagra enteramente, según el cual las acciones están vinculadas por las necesidades de la trama, conformes a su plan. La laxa temporalidad de las cosas y de los acontecimientos materiales que simplemente vienen uno después del otro, se opone a la construcción razonada de una apretada trama argumental, según esos juegos precisos "de vigilancias, ecos placeres afinidades" que, para Borges, diferencian la ficción de la vida (1982: 90).

Pero Emma, la obrera que viene del mundo oscuro de las actividades materiales, no da puntada sin hilo: el cuento de Emma, "lúcido y limitado", producto de un conjunto de operaciones racionales, está tejido con los hilos invisibles de una realidad holgada que no hacen sospechar en ninguna figura en el tapiz. El cuento de Emma tiene la textura de una novela "sobre nada", arraigada en la vida que Emma pone a trabajar a su favor, donde la sucesión de hechos empíricos disimula las costuras y los anudamientos necesarios de la intriga. La mera "transcripción de la realidad" propia de las novelas realistas o de "simulación psicológica" (El arte narrativo, 91) y la causalidad artificial del cuento, firme y apretada, se entretejen como en un tejido; la urdimbre se entrecruza con la trama[1].. ${ }^{5}$

\section{Una cualquiera: hilos sueltos}

Pero hay un momento en el que las conexiones de la racionalidad ficcional, esas que vuelven creíble lo imposible, corren el riesgo de perderse. Se trata de un tiempo "fuera del tiempo", en el que reina para Emma un "desorden perplejo de sensaciones inconexas y atroces", porque el todo - el plan - que les da sentido se deshilvana (Borges, 2001: 72). Haciendo de prostituta, mientras recorre los bares en busca de un hombre que se acueste con ella y que le dé las razones suficientes para castigar y matar a Loewenthal, ¿habrá pensado Emma en el padre muerto, que motivó su sacrificio? "Yo tengo para mí que pensó una vez y que en ese momento peligró su desesperado propósito" -especula uno de esos narradores en primera de los cuentos de Borges que muestran la hilacha de un artificio sin más puntas sueltas que las que quedan señaladas por su intervención. Y lo que pensó con asombro y horror, o mejor dicho, lo que "no pudo no pensar" sin perder la cabeza y según otro tipo de lógica que la del

5 En una tela, se llama "urdimbre" al conjunto de hilos longitudinales tensados sobre el bastidor del telar, mientras que la "trama" son los hilos que se entrecruzan con la urdimbre a lo ancho de la tela. 
verosímil, es que eso que el marinero estaba haciendo con su cuerpo era para Emma "la cosa horrible" que su padre "le había hecho a su madre" (ibídem: 73).

La singularidad de una historia se anuda aquí con la fuerza de la pulsión. ¿Qué es ese exceso en relación con el ideal representativo que dispone las partes y el desenlace en forma armoniosa y equilibrada? ¿Cómo nombrar ese oscuro empuje sin nombre, en serie con el temor "casi patológico" que le inspiran los hombres (ibídem: 70), subiendo del fondo de la memoria corporal de Emma bajo la figura de una madre borrosa expropiada de su deseo por un padre que se queda con el patrimonio del goce?

Al desplazarse del padre a la madre, Emma pasa del problema de la sangre y toda su simbólica de la venganza (la sangre recibida del padre, transmitida, contaminada, infectada, mezclada, arriesgada y derramada en, por ejemplo, un cuento como "El Sur"), al sexo como terreno donde la transparencia de la persona le deja lugar a la opacidad del cuerpo en lo que este tiene de material y viviente. Son los cuerpos que viven, hablan y trabajan; cuerpos dóciles inmersos en la esfera de reproducción de lo viviente; cuerpos libidinizados, como lugar de elaboración de la ley que determina los límites de nuestro pensar y nuestro sentir en general, sin los cuales el capitalismo fordista para el que trabaja Emma no podría funcionar.

Pero entonces esa cosa "horrible" en la que la hacen pensar los golpes de cadera del marinero, ese horror al cuerpo como lugar de placer, ¿no está expresando el secreto del fetichismo de la mercancía, al que Emma, en el rol de prostituta, puede acceder después de haber vendido su cuerpo a cambio de dinero en el mercado del deseo? ¿Habrá pensado Emma Zunz una sola vez en la prostitución como espejo que refleja la lógica secreta de la explotación capitalista, que compra el tiempo de vida de los cuerpos a cambio de dinero? Yo tengo para mí que no pensó, si por pensar entendemos tomar conciencia de los mecanismos de la dominación. Si hubiera sido así, estaríamos tocando el núcleo mismo de la literatura social y de las interpretaciones sociológicas, a saber, el devenir cosa de las relaciones humanas cifrado en la figura de la prostituta que rompe el dinero y, proletarizada, mata en el espacio oscuro de la fábrica a Loewenthal, el patrón rompehuelgas representante del poder que opera la metamorfosis del trabajo vivo en su contrario, el trabajo muerto. ${ }^{6}$

Pero concentrarse en la relación de explotación que pone en serie a la mujer, la prostituta y la trabajadora, expropiadas de su goce y de su fuerza de trabajo, ¿no implica reducir la multiplicidad de relaciones de poder a la relación económica? A la hora de hacer cuerpos y de pensar en su inserción controlada en los procesos económicos, el sometimiento, la servidumbre, la renuncia al placer, la dominación patriarcal internalizada y la violencia de género, sedimentadas en la memoria y el cuerpo de Emma, no son menos decisivos que la categoría del trabajo.?

Estamos del lado de los procesos de constitución material de las subjetividades, más acá de la alienación y de la idea puramente abstracta del sujeto que vende su fuerza de trabajo como mercancía amputada de su realidad humana. Aquí, el trabajo en su especificidad concreta, hace cuerpo con el trabajador que, en tanto cuerpo vivo, retiene entre sus pliegues la capacidad de desujetarse respecto de las determinaciones del poder. Emma maquina un acto que permite imaginar y articular en la realidad virtual de la ficción nuevos dominios

6 Ver Rozitchner (2003), quien localiza la implantación del modo de dominación capitalista al nivel de una subjetividad que vive la materialidad del cuerpo como "residencia de lo temible en uno mismo que hay que domeñar" (2003: 24). Experimentado como naturaleza animal, el trabajo de la pulsión se vuelve algo extraño y ajeno para el sujeto, alejado de su cuerpo a la manera en que la corporeidad del trabajador es negada en el trabajo asalariado por la ley “paterna” del capital. Así, para Rozitchner, la lucha contra el poder que se opone a la satisfacción del deseo es la esencia misma del hombre. 7 "La estructura económica y la fábrica", observa Lazzarato, "presuponen los mecanismos disciplinarios que ya actúan sobre las almas y los cuerpos” (2006: 83). 
de subjetivación y de relación con el propio cuerpo, muy diferente de la idea de que el capitalismo transforma al trabajador en máquina y lo aliena. ${ }^{8}$

Emma pensó en el padre que goza unilateralmente como nudo de un poder con raíces en el cuerpo - un cuerpo que retiene entre sus pliegues un pasado virtual vinculado al deseo impensado de la madre, en espera de ser actualizado. ${ }^{9}$ Digamos entonces que a pesar del asco y la tristeza de su cuerpo (ibídem: 73), Emma salió viva del encuentro con el marinero, cosida a un cuerpo que no sabía que tenía, con la capacidad de afectar y ser afectada, fortalecida. Porque avivada por lo que acaba de sucederle, Emma no se deja hacer lo que su padre le había hecho a su madre: encarna otra sensibilidad, que es potencialmente otra distribución del deseo y de la capacidad de actuar que desborda la oposición activo-pasivo o libertad-obediencia. La imagen victimizada de la madre, elevada a cuasi-causa de la acción, debería desvanecerse desde el momento en el que Emma, según una suerte de pragmática vitalista, se sirve del ultraje para hacerse un cuerpo y motorizar un acto de venganza que asume el cálculo afectivo como motor de la acción. Emma recibe del pasado un inesperado ímpetu vital que contrasta con lo que hay de frío, impasible y calculador en la racionalidad del plan original, que convierte el encuentro con el marinero, de coartada estratégica, en impulso verdadero de venganza ya no del padre, sino de la madre invisible y postergada en su deseo.

¿Qué es entonces lo que peligra en ese momento de vértigo, "fuera del tiempo", donde un cuerpo ensaya con una nueva afectividad y racionalidad? Lo que vacila en Emma, junto con el conjunto de identificaciones y asignación de roles de género, ¿no es el principio de acción que sostiene la racionalidad ficcional de su cuento? Aplastada contra la materialidad de su cuerpo por el peso insoportable del marinero, Emma se enfrenta con un problema de construcción, a saber, “¿Cómo hacer verosímil una acción en la que casi no creyó quien la ejecutaba" (ibídem: 71)? ¿Cómo ser creíble cuando las partes que forman el relato "no parecen consecutivas" (ibídem: 72)? Por un instante, Emma se asomó a otro tiempo que el de las acciones encadenadas según el principio de verosimilitud: el tiempo de un mundo de sensaciones desconocidas, prostituido por detalles ligados al cuerpo y al sexo como lugar de una nueva inteligibilidad que desborda el diagrama de roles y lugares asignados por la lógica de la dominación.

En el umbral mismo en el que los dispositivos de poder hacen cuerpos dóciles e individuos sumisos, Emma entrevé otra historia, que es también otra literatura, ligada a la sexualidad como terreno donde se anudan y desanudan cuerpos y significaciones: donde la vida, codificada bajo el signo del capital y de la productividad, se vuelve potencialmente contra el sistema que pretende controlarla. Hay allí un hilo suelto, un extravío del principio de acción y de asignación de roles del que Emma, conforme al diseño inicial de su plan, no hubiera querido apartarse. Pero la acción que la vuelve por un rato instrumento del placer del marinero queda subordinada a la creación de una bifurcación que abre un nuevo campo de percepciones, de funciones y de afectos inseparables de una nueva vitalidad social que va en sentido inverso al principio de acción estratégica, fría y razonada, que queda restablecido una vez que Emma abandona el cuarto y se va del puerto a reunirse con Loewenthal.

Emma va rumbo a la fábrica, y el hecho de elegir los asientos delanteros del tranvía para que nadie le viera la cara la muestra recuperada y con la situación bajo control, al mando de las acciones y de la enunciación corporal de su historia. La jerarquía de tiempos ha sido restablecida, y Emma mira con alivio "el insípido trajín de las calles" por la ventanilla del vagón, porque, especula el narrador, "quizá le confortó verificar

8 Acerca del cuerpo definido por sus capacidades, indisociables del sujeto trabajador, ver el análisis de Foucault del capital humano (2004: 230).

9 Para una lectura centrada en el cuerpo "spinozista" de Emma y sus poderes indeterminados, ver Sarlo (1999). 
(...) que lo acaecido no había contaminado las cosas" (73). Pero lo acaecido, que en tanto transformación incorporal, actuó en primer lugar al nivel del espíritu, tiene a la vez una dimensión material, ligada a un cuerpo que lleva entre sus pliegues la huella material de la "cosa horrible" que, en su laboriosa y calculada pasividad, Emma se dejó hacer, sin haber pensado en los efectos. Cambió la sensibilidad y la distribución de los deseos, pero cambió también algo al nivel de un cuerpo que no salió intacto del encuentro, contaminado por una mezcla de afectos que desborda la idea fría y restringida que preside la construcción del enigma.

Esta dimensión material y viviente que corre por debajo de la estructura de racionalidad de la historia, ¿no estaría poniendo en serie los varios cuerpo a cuerpo que entabla Emma a lo largo de la historia con la tradición de los ilegalismos populares? Después de todo, en la tradición de los ilegalismos populares (Ludmer, 1992), Emma es la heroína que hace justicia enfrentándose físicamente con el poder y burlándose de la ley. Pero hay un narrador, que no va a permitir que Emma sea el criminal rústico de las leyendas populares, sino una artista del crimen, autora de un crimen perfecto. $\mathrm{El}$ asesinato de Loewenthal es una obra de arte - una muerte autónoma, estetizada que, en su excepcionalidad, separa a Emma de las de su clase y de su género. Dueña de una inteligencia y de una voluntad superiores, capaz de actuar en el reverso de la ley y salirse con la suya, Emma es una plebeya que cruza umbrales de visibilidad y legibilidad para pasar a formar parte de una aristocracia del crimen, sin poner en tela de juicio el principio de acción que pone a las "obras de imaginación razonadas" (2006: 10) por encima de cualquier otro tipo de política estética.

Historia de un crimen perfecto, "Emma Zunz" no es sin embargo un cuento policial: no hay investigación del crimen, ni un Lönnrot, el detective de "La muerte y la brújula", a quien la muerte en defensa propia alegada por Emma le parezca "posible, pero no interesante" (2001: 155). Más que lucha intelectual entre dos razonadores, hay complicidad y connivencia de parte del narrador, si bien no encubrimiento, desde el momento en que acaba con la apariencia de realidad al mostrar las conexiones artísticas del texto. Pero en su tratamiento de la causalidad ficcional, "Emma Zunz" funciona como un cuento policial, el género literario que surgió a mitades del siglo XIX para conjurar el peligro que las multiplicidades de la vida moderna representaban para un orden narrativo que pretendía tomar distancia de la crónica policial del crimen popular, con toda su ambigua glorificación del criminal. "La literatura policiaca traspone a otra clase ese brillo que rodeaba al criminal", dice Foucault en Vigilary castigar, y el criminal legendario de los géneros populares, el hombre violento e impulsivo o la simuladora que se enfrenta cuerpo a cuerpo con el poder, es ahora "demasiado sencillo para ser el protagonista de las verdades sutiles" de las que participan silenciosamente inteligencias superiores y sutiles como las del personaje principal de un cuento que deja en pie las jerarquía de la acción (Borges, 2001: 74).

Hay entonces dos Emmas enfrentadas dentro de un texto que pone a Borges en contra de sí mismo: la Emma aristócrata del crimen a la que la narración le transfiere la autonomía estética, tejedora, tejedora de tramas a medida y elaborados enigmas, y la Emma desconectada de la máquina narrativa, una cualquiera perdiéndose en el tejido de afectos y sensaciones de la vida anónima, para devenir imperceptible. El desvío de Emma por un arte de hacer, pensar y sentir las cosas sin representación ni cálculo de riesgos, dislocado temporalmente, en el que la performance es inseparable de la vida, anuncia un arte devenido forma de vida que no distingue entre grandes heroínas, diseñadoras de elegantes diseños ficcionales y trabajadoras anónimas de la ficción, habitando otra vida y otro tiempo, que es también otra literatura. 


\section{Dibliografía}

"Angilletta, F. (2018). "Vidas de las trabajadoras: apuntes sobre "Emma Zunz". En Escritores del mundo, diciembre de 2017-9 de agosto de 2018. En línea: www. escritoresdelmundo.com/2018/o1/vidas-de-las-trabajadoras-apuntes-sobre. html

" Badiou, A. (2005). El siglo. Pons, H. (trad.). Buenos Aires, Manantial.

»Borges, J. L. (1982).“El arte narrativo y la magia“. En Discusión. Buenos Aires, Emecé.

» ------ (1987). Evaristo Carriego. Buenos Aires, Emecé.

»----- (2001a). Emma Zunz“. En El Aleph. Buenos Aires, Alianza/Emecé.

»------- (2001b). La muerte y la brújula. En Ficciones. Buenos Aires, Alianza/ Emecé.

"------ (2006). Prólogo. En Bioy Casares, A. La invención de Morel. Buenos Aires, Alianza/Emecé.

" Foucault, M. (1989). Vigilar y castigar. El nacimiento de la prisión. Garzón del Camino, A. (trad.). Buenos Aires, Siglo XXI.

》------- (2004). Naissance de la biopolitique. Cours au College de France, 1978-1979. París, Gallimard.

» Gago, V. (2014). La razón neoliberal. Economías barrocas y pragmática popular. Buenos Aires, Tinta Limón.

» Guy, D. J. (1994). El sexo peligroso. La prostitución legal en Buenos Aires (1875-1955). Buenos Aires, Sudamericana.

" Huyssen, A. (2006). La cultura de masas como mujer: lo otro del modernismo. En Después de la gran división. Modernismo, cultura de masas, posmodernismo. Gianera, P. (trad.). Buenos Aires, Adriana Hidalgo,

" Kohan, M. (2013). De putas. Fuga de materiales. Selección y edición de Leila Guerrero. Santiago de Chile: Ediciones Universidad Diego Portales.

"Lazzarato, M. (2006). Política del acontecimiento. Rodríguez, P. (trad.). Buenos Aires, Tinta Limón.

》 Louis, A. (1997). Jorge Luis Borges. CEuvres y manœuvres. París, L'Harmattan.

»Ludmer, J. (1992). Las justicias de Emma. Cuadernos Hispanoamericanos, núm. 505/507, julio/septiembre.

»------ (1999). El cuerpo del delito. Un manual. Buenos Aires, Perfil.

» Molloy, S. (1994). La política de la pose. En Ludmer, J. (coord.). Las culturas de fin de siglo en América Latina: Coloquio en Yale, 8 y 9 de abril de 1994, pp. 198-208, Rosario, Beatriz Viterbo.

» Munck, R.; Falcón, R. y Galitelli, B. (1987). Argentina. From Anarquism to Peronism. Workers, Unions and Politics, 1855-1985. Londres/New Jersey, Zed Books.

»Panesi, J. (1997). Mujeres: la ficción de Borges. En Lukin, L. (ed.). Narrativa argentina. Décimo encuentro de escritores Dr. Roberto Noble. Buenos Aires, Fundación Roberto Noble. 
»Piglia, R. (1993). Roberto Arlt. La ficción del dinero. En La Argentina en pedazos. Buenos Aires, La Urraca.

"Rancière, J. (2007). Borges et le mal français. En Politique de littérature. París, Galilée.

»----- (2015). El hilo perdido. Ensayos sobre la ficción moderna. Rodríguez, M. del C. (trad.). Buenos Aires, Manantial.

»-------- (2017). Les aventures de la causalité. En Les bords de la fiction. París, Seuil.

» Rozitchner, L. (2003). Freud y el problema del poder. Buenos Aires, Losada.

"Sarlo, B. (1999). El saber del cuerpo. A propósito de "Emma Zunz". En Variaciones Borges 7, pp. 231-247.

»Scavino, D. (1999). La era de la desolación. Ética y moral en la Argentina de fin de siglo. Buenos Aires, Manantial.

"Shklovsky, V. (2002). El arte como artificio. En Todorov, T. (ed.).Teoría de la literatura de los formalistas rusos, pp. 55-70. Nethol, A. M. (trad.). Buenos Aires, Siglo XXI. 